\title{
Crush syndrome due to earthquake subsidence
}

Nuray Enç, BSN, MSN, PhD, Associate Professor, Department of Medical Nursing, Florence Nightingale Nursing College, Istanbul University, Istanbul, Turkey

Dogancılar Cd. Demet Apt. No. 55/8, Üsküdar/Istanbul, Turkey. e-mail: nurayenc@yahoo.com

\section{INTRODUCTION}

Crush syndrome is one of the many types of damage encountered in the aftermath of an earthquake. It was first reported following the Messina earthquake in 1909 and during World War II in Germany. The first description of acute renal failure (ARF) caused by crush syndrome in modern English literature dates back to Bywaters and Beall's description in bombing victims found in London during the Battle of Britain in World War II (Better, 1990; Better, 1997; Yavuz, 1999).

Since then, a number of crush syndrome cases have been reported during epidemics, wars and other social incidents. During the last quarter of the 20th century, major earthquakes were the main cause of most cases of crush syndrome, including earthquakes in 1976 in Tangshan, China, in 1980 in South Italy, in 1988 in Armenia and in 1995 in Honshin-Awaji, Kobe, Japan (Abassi et al., 1998).

Major earthquakes are followed by a substantial number of crush syndromes, provoking rhabdomyolysis and pigmentinduced ARF (Vanholder et al., 1999). The incidence of crush syndrome has been estimated at 2-5\% (Better et al., 1992; Better et al., 1993; Better et al., 1997; Vanholder et al., 1999). Approximately $50 \%$ of patients with crush syndrome develop ARF, of whom about 50\% will need dialysis (Ron et al., 1984; Vanholder et al., 1999). Table 1 summarises the reported experiences with major earthquakes during the period from 1985 to 1999 (Vanholder et al., 1999). In the Marmara earthquake, the proportion of dialysed patients with ARF was very high.

The clinical crush syndrome occurs as a consequence of traumatic events, either accidents or disasters. In contrast with accidents involving only a few individuals, disasters can affect many victims simultaneously, all of whom may require medical care.

\begin{tabular}{|c|c|c|c|c|}
\hline Location & Year & Mortality (n) & $\begin{array}{l}\text { Crush } \\
\text { syndrome (n) }\end{array}$ & $\begin{array}{l}\text { Dialysed } \\
\text { patients (n) }\end{array}$ \\
\hline Mexico City, Mexico & 1985 & 7,000 & $?$ & - \\
\hline Spitak, Armenia & 1988 & 25,000 & 600 & 323 \\
\hline Loma Prieta, USA & 1989 & 63 & $?$ & $?$ \\
\hline Northern Iran & 1990 & 50,000 & $?$ & 156 \\
\hline Erzincan, Turkey & 1992 & 547 & $?$ & 6 \\
\hline California, USA & 1994 & 33 & $?$ & $?$ \\
\hline Kobe, Japan & 1995 & 5,000 & 372 & 123 \\
\hline Marmara, Turkey & 1999 & 17,000 & 639 & 476 \\
\hline
\end{tabular}

As a result of compression, muscular cells are damaged, followed by the release of intracellular contents into the systemic circulation. This process is called rhabdomyolysis. One of the key compounds released is myoglobin. Myoglobin is filtered by renal glomeruli and transferred into the renal tubules, where it causes obstruction and functional failure (Yavuz, 1999). Other intracellular components, such as nucleotides, precursors of uric acid, proteins, phosphate and potassium, are also released from the damaged muscle cells. These have an important pathophysiological impact, as well as causing volume depletion of the victim. Today, rhabdomyolysis is one of the leading causes of ARF (Yavuz, 1999).

However, it should be noted that most cases of rhabdomyolysis occurring during peacetime are provoked by non-traumatic processes, mainly alcohol abuse, muscular compression due to coma or seizures, electrolyte disturbances (hypokalaemia, hypophosphataemia), exertion, hyperthermia, drug ingestion and infectious diseases (Yavuz, 1999). It should also be remembered that muscular trauma does not necessarily lead to rhabdomyolysis. Similarly, rhabdomyolysis does not always result in ARF; other causes of ARF include dehydration, sepsis and drug nephrotoxicity.

\section{PATHOPHYSIOLOGY OF ARF RELATED TO CRUSH SYNDROME}

Substantial advances have been made in the understanding of mechanisms responsible for ARF in rhabdomyolysis, including the following:

- Volume depletion per se is commonly a critical factor that decreases renal perfusion.

- Circulating myoglobin may bind to nitric oxide and facilitate renal vasoconstruction.

- Urine is often concentrated, which increases the concentration of myoglobin in the tubular fluid, thus increasing its propensity to form a gel.

- Urine is often intensely acidic, which promotes interaction of myoglobin with Tamm-Horsfall proteins, causing cast formulation and tubular obstruction.

- Myoglobin is absorbed by proximal tubular cells, stimulating production of injurious cytokines and free radicals resulting in acute tubular necrosis. This process is enhanced if there is flow resistance due to casts, which results in reduced elimination of myoglobin from proximal 
tubular fluid. The goal of treatment is to expand the circulation to improve renal perfusion, to remove the pigment from the kidney by accelerating urine flow and to solubilise pigment by alkalinising the urine to prevent obstructive cast formation (Better et al., 1992; Erek, 2000).

\section{CLINICAL AND LABORATORY FINDINGS}

In a conscious, cooperative patient, the clinical findings are cramp-like pain in the related muscle, swelling, muscular tension and progressive loss of strength (Bozkurt, 2000; Erek, 2000).

Laboratory findings include myoglobinuria and signs of renal failure, such as hyperkalaemia, hyperphosphataemia, hyperuricaemia and elevated serum levels of creatinine phosphokinase (CPK), aspartate aminotransferase (AST), alanine transferase (ALT) and lactic dehydrogenase (LDH).

\section{COMPLICATIONS}

The local effects of damage to muscular cells and the systemic effects of the material released by the damaged cells into the circulation result in acute biochemical and haemodynamic abnormalities. Complications take between days and hours to appear.

\section{Hypovolaemia}

Penetration of liquid into the damaged muscle results in hypovolaemia that might even lead to hypovolaemic shock. There may be a liquid loss of as much as 14 litres from damaged muscle (Better et al., 1992; Abassi et al., 1998). Replacement volume may exceed 10 litres per day. Invasive monitoring is needed to assess the volume of liquid loss (Bozkurt, 2000; Erek, 2000).

\section{Electrolyte disorders}

There are several points to consider:

- Excretion of large amounts of potassium causes lifethreating hyperkalaemia. This complication often develops as a result of oliguric ARF. The potassium level of the patient should therefore be measured frequently.

- Excretion of a significant amount of phosphate causes hyperphosphataemia.

- Purine excretion from damaged muscle and their transformation into uric acid in the liver result in uraemia. Damage to muscle cells results in the excretion of a considerable amount of sulphur-containing proteins. High levels of excreted hydrogen and sulphate ions may lead to anion-gap acidosis. Other reasons for acidosis may be lactic acidosis due to ischaemia or uraemic acidosis.

- Hypocalcaemia occurs in the acute phase of renal failure. Its aetiology is multifactorial and it clinically worsens crush syndrome. Constrictions make muscle damage worse and increase fractures.

- Hypercalcaemia occurs during the diuretic phase of renal failure, developing as renal failure begins to recover. Hypercalcaemia becomes noticeable between days and weeks after the acute phase of renal failure.

\section{Acute renal failure}

Acute renal failure is a complication of rhabdomyolysis. Experimental studies have shown that there are two critical factors involved in ARF:

- Hypovolaemia or dehydration

- Acidaemia.

\section{Disseminated intravascular coagulation}

Disseminated intravascular coagulation (DIC) is caused by the release of products from the damaged muscle cells. These products activate the coagulation cascades.

\section{Infection}

Fever and leucocytosis should be anticipated in patients with massive rhabdomyolysis. These changes appear to be the result of tissue destruction and do not necessarily indicate the presence of infection. However, both sepsis and pneumonia are common. Acute respiratory distress syndrome is also seen in severe cases of crush syndrome (Thelan et al., 1998).

\section{Compartmental syndrome}

Compartmental syndrome is a condition in which increased pressure within a limited space compromises circulation, resulting in ischaemia and tissue necrosis. Among patients at high risk for the development of compartment syndrome are those with trauma of the lower extremities, including fractures, penetrating trauma, vascular ruptures, massive tissue injuries or venous obstruction. Clinical manifestations of compartment syndrome include obvious swelling and tightness of an extremity, paresis and pain of the affected extremity. Diminished pulses and decreased capillary refill do not reliably identify compartment syndrome because they may be intact until after irreversible changes have occurred.

Treatment consists of simple interventions, such as removing an occlusive dressing, to more complex interventions, including fasciotomy. Meticulous wound care after fasciotomy is imperative to prevent wound infection (Thelan et al., 1998; Erek, 2000).

\section{MANAGEMENT OF CRUSH SYNDROME}

There are two aspects to treatment. These are:

- Treatment of the reversible muscle damage, which means that the patient must be removed from the scene of disaster.

- Prevention of complications and their treatment, which usually involves intensive care.

\section{Hypovolaemia}

In hypovolaemia, a more aggressive liquid replacement regimen should be initiated. Treatment should begin while the extremity is still under pressure or compressed. The rate of replacement should be increased as soon as compression on the whole body is lifted. Initial treatment involves administering between 2 and 3 litres of plasma. Following haemodynamic stabilisation, the amount of serum should be reduced to $300-500 \mathrm{ml} / \mathrm{h}$.

\section{Volume replacement}

The most common mistake made in the treatment of crush syndrome is inadequate volume replacement (Bozkurt, 2000; Erek, 2000). The aim of boosting volume is to speed up glomerular filtration, to increase diuresis and to prevent the coagulation of intraluminal haem proteins, such as myoglobulin. It is essential to monitor volume in an oliguric patient with myoglobinuric failure using central venous or pulmonary artery pressure (Bozkurt, 2000; Erek, 2000).

\section{Sodium bicarbonate therapy}

As urine alkalinisation has a preventative effect, intravenous sodium bicarbonate should be administered to the patient. The 


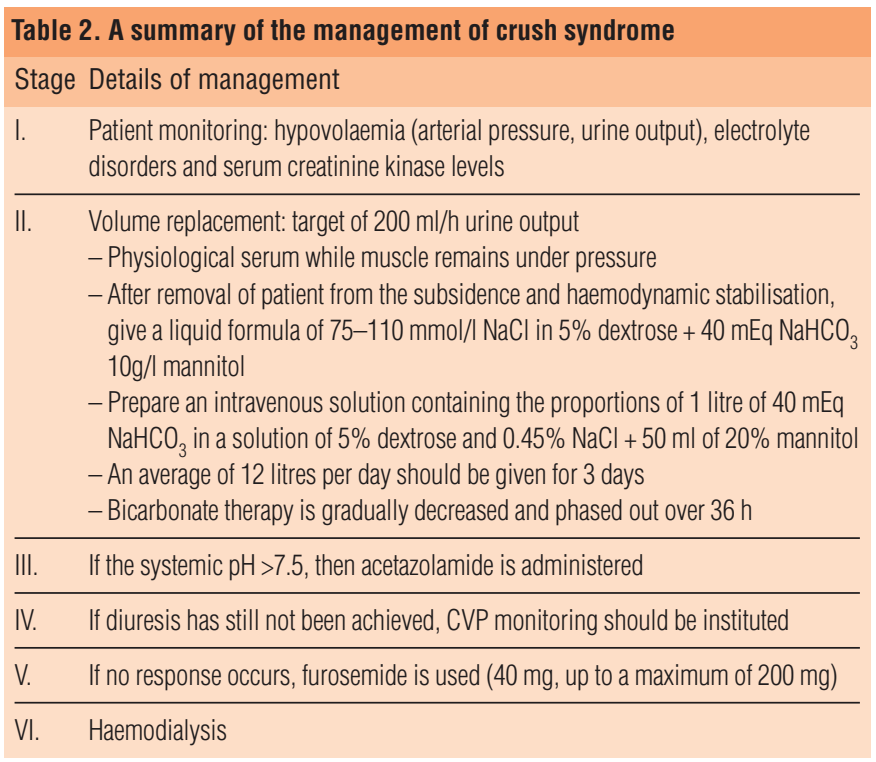

aim is to keep urine $\mathrm{pH}$ above 6.5. If the arterial $\mathrm{pH}$ is higher than 7.5 , it may be helpful to use acetazolamide.

\section{Electrolyte abnormalities}

Electrolyte abnormalities require treatment during the acute phase of renal failure. In particular, hyperphosphataemia requires electrocardiographic monitoring, close monitoring and treatment when the serum potassium level is higher than 6 $\mathrm{mEq} / \mathrm{l}$. The best treatment for electrolyte abnormalities is dialysis.

\section{Prevention of ARF}

In experimental myoglobinuria, it has been shown that intravenous mannitol may help to prevent ARF.

\section{Haemodialysis}

Haemodialysis should be started as early as possible.

\section{Dietary recommendations}

The patient's diet should consist of high-calorie carbohydrate foods. Any food that increases potassium levels should be strictly avoided (Bozkurt, 2000; Erek, 2000).

\section{NURSING CARE}

\section{Monitoring}

Assessment and ongoing monitoring of renal function are critical to the survival of the trauma patient. Haemodynamic parameters (pulmonary artery wedge pressure [PAWP] and cardiac index, $[\mathrm{CI}]$ ), urine output, serum creatinine and blood urea nitrogen (BUN) will provide information about fluid balance and kidney function.

\section{Anxiety}

Anxiety in the patient is related to threat to biological, psychological and/or social integrity. Nursing management involves:

Providing a safe place for the patient.

- Reassuring and calming the patient.

- Behaving in a way that gains the confidence of the patient.

Enabling the patient to express his/her concerns.
Listening to the patient.

- Making the patient feel he/she is being cared for.

- Administering anxiolytics, as directed by a physician.

\section{Pain}

Pain relief is a major component in the care of trauma patients. An issue that often complicates pain management is the high incidence of substance abusers who sustain traumatic injury (Thelan et al. 1998; Students of French Valencienne Nursing College, 2000). Nursing care involves the assessment of pain, administering pain-relieving medication as directed by a physician, and determining the effect of pain relief.

\section{Infection control}

The critical care patient with ARF is at risk for infectious complications. Concern should be raised by signs of infection, such as increased white blood cell (WBC) count, redness at a wound or intravenous site, or increased temperature. Pulmonary hygiene is maintained by asking the patient to cough and deep breathe frequently, by suction if the person is intubated and ventilated, and by frequent positional changes. An immobile patient should be turned frequently and potential sites for skin breakdown should be carefully observed; these precautionary measures will reduce the development of infection. If significant anasarca (severe generalised oedema) has developed, the use of a circulating or air-fluid mattress may help prevent skin breakdown.

\section{Fluid balance}

The frequent assessment of intake and output is a necessary part of nursing management for the patient in ARF. Haemodynamic values and daily weights should be correlated with fluid intake and output to monitor potential fluid overload.

\section{Electrolyte balance}

Hyperkalaemia, hypocalcaemia, hyponatraemia, hyperphosphataemia, and acid-base imbalance all occur during ARF (Thelan et al., 1998). Clinical manifestations of these electrolyte imbalances must be prevented and their associated side-effects controlled. Imbalances with the most potential hazards are hyperkalaemia and hypocalcaemia, which can result in lifethreatening cardiac dysrhythmias, while hyperphosphataemia results in severe pruritis. Nursing care is directed at soothing the itching by performing frequent skin care with emollients, discouraging scratching, and administering phosphate-binding medication. The acid-base imbalances that occur with ARF are monitored by arterial blood gas analysis.

\section{Myoglobinuria}

Patients with a crush injury are susceptible to the development of myoglobinuria, with subsequent secondary renal failure. Myoglobinuria frequently develops within six hours after injury. Signs of myoglobinuria include dark red, or burgundy-coloured, urine and decreasing urine output. Recognition of patients at risk for the development of myolobinuria is imperative to its prevention. Such prevention includes early external immobilisation of fractures and early serial urine testing for myoglobin.

\section{Fluid and electrolyte balance}

Nursing management is directed toward the achievement of fluid and electrolyte balance. Assessment parameters may include maintaining urine output greater than equal to $100 \mathrm{ml} / \mathrm{h}$ and maintaining urine $\mathrm{pH}$ greater than or equal to 7.0 (Thelan et al., 1998). 


\section{Patient education}

The nurse must give accurate and uncomplicated information to the patient and family about ARF, including its prognosis, treatment and possible complications. Education can be challenging because elevations of BUN and creatinine can reduce the level of consciousness. In addition, sleep-rest disorders and emotional upset often occur as complications of ARF and can disrupt short-term memory.

\section{Dialysis}

A wide range of options is available for the treatment of ARF, including haemodialysis, peritoneal dialysis and continuous renal replacement therapy (Thelan et al., 1998). It is essential for the nurse to become familiar with each type of dialysis, including their potential problems and nursing interventions.

\section{Missed injury}

The critical care nurse must be alert to the possibility of a missed injury, especially when the patient does not appear to be responding appropriately to interventions. The physician must be notified immediately because the potential complications of infection and haemorrhage can be life-threatening.

\section{REFERENCES}

Abassi ZA, Hoffman A, Better OS. (1998). Acute renal failure complicating muscle crush injury. Seminars in Nephrology; 18: 558-565.
Better OS, Rubinstein I, Winaver J. (1992). Recent insights into the pathogenesis and early management of the crush syndrome. Seminars in Nephrology; 12: $217-222$.

Better OS. (1990). Early management of shock and prophylaxis of acute renal failure in traumatic rhabdomyolysis. New England Journal of Medicine; 322: $825-829$.

Better OS. (1993). Acute renal failure in casualties of mass disasters. Kidney International; 43: 235-236.

Better OS. (1997). History of the crush syndrome: from the earthquakes of Messina, Sicily 1909 to Spitak, Armenia 1988. American Journal of Nephrology; 17: 392-394.

Bozkurt P. (2000). First aid and anaesthesia in crush syndromes. In: Ertugrul G, Feridun S, (eds.), Crowd Injuries and Disaster Medicine. (Publication number 19). I.Ü. Cerrahpasa Medical Faculty Committee of Continuing Medical Education, pp. 155-164.

Erek E. (2000). Diagnosis and treatment in crush syndrome due to subsidence. In: Ertugrul G., Feridun S, (eds.), Crowd Injuries and Disaster Medicine. (Publication number 19). I.Ü. Cerrahpasa Medical Faculty Committee of Continuing Medical Education, pp. 165-171.

Ron D, Taitelman U, Michaelson M, et al. (1984). Prevention of acute renal failure in traumatic rhabdomyolysis. Archives of Internal Medicine; 144: 277-280.

Students of French Valencienne Nursing College. (2000). Rhabdomyolysis. A mutual scientific meeting of students of I.Ü. F. N. Nursing College and French Valencienne Nursing, 4-6th July.

Thelan LA, Urden LD, Lought ME, Stacy KM. (1998). Critical Care Nursing Diagnosis and Management. (3rd ed.) St. Louis: Mosby, pp. 1089-1091.

Vanholder R, Sever MI, Smet Md, Erek E, Lameire N. (1999). The Intervention of The Renal Disaster Relief Task Force in The North-West Turkey Marmara Earthquake. (Personal communication, August 17th 1999).

Yavuz M. (1999). Crush syndrome and acute renal failure. Journal of the Turkish Nephrology Association; 163-166. 